Journal of Machine Engineering, 2020, Vol. 20, No. 2, 94-103

ISSN 1895-7595 (Print) ISSN 2391-8071 (Online)

Received: 14 November 2019 / Accepted: 18 December 2019 / Published online: 24 June 2020

aluminum-silicon alloys, end mill, tool wear, cemented carbide tool

\author{
Yuya KOBARU ${ }^{*}$ \\ Ryo NAGAOKA ${ }^{1}$ \\ Kenji SHIMANA ${ }^{1}$ \\ Shinichi YOSHIMITSU ${ }^{1}$ \\ Eiji KONDO ${ }^{2}$
}

\title{
TOOL WEAR CHARACTERISTICS IN MACHINING OF HYPEREUTECTIC Al-Si ALLOYS BY CEMENTED CARBIDE TOOL
}

\begin{abstract}
During of hypereutectic Al-Si alloys, tool wear increases owing to the presence of silicon particles. Therefore, polycrystalline diamond tools are typically used, but they are very expensive. The purpose of this study is to examine the tool wear characteristics during the end milling of hypereutectic Al-Si alloy (A390-T6) by using comparatively inexpensive diamond-like carbon coated cemented carbide tools. Al-Si alloy was end-milled by changing the cutting speed. Our results revealed that the width of flank wear land increased monotonously with increasing of the cutting force regardless of the cutting speed. In addition, the experimental equation of the width of flank wear land was derived as a function of cutting speed and time, and it was clarified that width of flank wear land could be approximated.
\end{abstract}

\section{INTRODUCTION}

Hypereutectic Al-Si alloys have been used in internal combustion engine parts, cylinder bodies of compressors and pumps, etc., owing to their low thermal expansion coefficient, high hardness, and good wear resistance [1,2]. The main processing methods for hypereutectic Al-Si alloys are forging, casting, and cutting. Among them, cutting, especially end milling, is considered to be suitable for processing hypereutectic Al-Si alloys, because it is possible to process complex shapes and finishes consistently.

In recently, many studies on end milling of difficult-to-cut materials have been conducted [3-6]. However, end milling of hypereutectic Al-Si alloys requires expensive tools such as polycrystalline diamond tools (PCD) and CVD diamond coated tools to avoid tool wearing due to the influence of Si crystal grains [7-9]. Therefore, the use of a relatively lowpriced cemented carbide as a tool material would help reduce the cost of cutting.

\footnotetext{
${ }^{1}$ National Institute of Technology, Kagoshima College, Depart. of Electronic Control Engineering, Kagoshima, Japan

${ }^{2}$ Kagoshima University, Graduate School of Science and Engineering, Kagoshima, Japan

*E-mail: kobaru@kagoshima-ct.ac.jp https://doi.org/10.36897/jme/117775
} 
Recently, the performance of cemented carbide tools has been improved with the development of tool coating technology, and the number of inexpensive coated tools has increased $[10,11]$. Therefore, we focused on the use of diamond-like carbon (DLC) coated carbide tools for cutting aluminum alloys. In the previous study, Bhowmick et al. have clarified the tribological behavior of hypereutectic Al-Si alloys by drilling with DLC coated cemented carbide tools [12]. Furthermore, they have investigated the characteristic of dry tapping as alternatives to conventional flooded tapping [13]. In terms of turning, it have been reported that DLC films prevent adhesion of aluminium on tool, decrease cutting forces, improve machined surface roughness and accuracy, facilitate chip evacuation and significantly reduce wear $[14,15]$. As mentioned above, a lot of knowledge about the machining of Al-Si alloys using DLC coated tools has been obtained, and these are extremely beneficial results to establish as a practical technology. On the other hand, with regard to end milling, research on machined surface properties has been conducted [16], but there are few reports on tool wear.

The purpose of this study is to clarify the tool wear characteristics during end milling of hypereutectic Al-Si alloy with a silicon content of 17\% (A390-T6) by using inexpensive DLC coated carbide tools. End milling of Al-Si alloy was performed while changing the cutting speed and the relationships between tool wear and cutting force, cutting speed, and cutting distance was investigated.

\section{EXPERIMENTAL APPARATUS AND METHODS}

A schematic of the experimental apparatus is shown in Fig. 1. Cutting tests were conducted on a five-axis machining center (Makino Milling Machine Co., Ltd.: D300). The workpiece was hypereutectic Al-Si alloy with silicon content of 17\% (A390-T6), and a $30 \mathrm{~mm} \times 60 \mathrm{~mm}$ surface was end milled in the longitudinal direction.

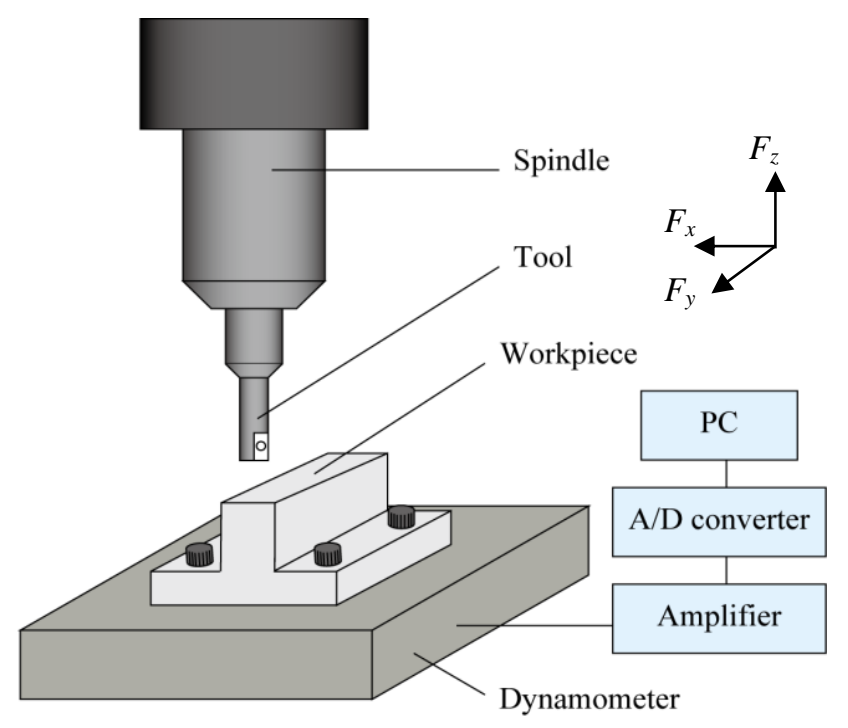

Fig. 1. Experimental apparatus 
The cutting tool used a throw-away tip with a diameter of $14 \mathrm{~mm}$ and one blade, cemented carbide coated DLC (Sumitomo Electric Hardmetal Co.: AXET 123508PEFR-S DL1000) was used for end milling of materials. For pre-processing, the surface of the workpiece was machined with a carbide square end mill having 2 blades and a diameter of $10 \mathrm{~mm}$ with a cutting depth of $0.5 \mathrm{~mm}$. During the cutting test, a cutting dynamometer (Kistler: 9257B) was used to measure the cutting force, which was measured at a certain cutting distance. Table 1 shows the cutting conditions. The cutting was performed by changing only the cutting speed, with the axial and radial depth of cut and feed rate being constant. The wear of the cutting edge was observed using a microscope (Keyence: VHX-1000).

Table 1. Cutting conditions

\begin{tabular}{|l|l|l|}
\hline \multirow{4}{*}{ Workpiece } & Material & A390-T6 \\
\cline { 2 - 3 } & Size $[\mathrm{mm}]$ & $60 \times 30$ \\
\hline \multirow{5}{*}{ Tool } & Material & DLC coated cemented carbide \\
\cline { 2 - 3 } & Diameter $[\mathrm{mm}]$ & 14 \\
\cline { 2 - 3 } & Rake angle $\alpha_{n}[\mathrm{deg}]$. & 0 \\
\cline { 2 - 3 } & Clearance angle $\gamma_{n}[\mathrm{deg}]$. & 11 \\
\cline { 2 - 3 } & Nose radius $r_{e}[\mathrm{~mm}]$ & 0.8 \\
\cline { 2 - 3 } & Number of flutes & 1 \\
\hline Radial depth of cut $a_{e}[\mathrm{~mm}]$ & 0.5 \\
\hline Axial depth of cut $a_{p}[\mathrm{~mm}]$ & 0.5 \\
\hline Feed rate $f_{z}[\mathrm{~mm} / \mathrm{rev}]$ & 0.05 \\
\hline Cutting speed $v_{c}[\mathrm{~m} / \mathrm{min}]$ & $150-300$ \\
\hline Type of cut & Down cut \\
\hline Cutting fluid & None (dry) \\
\hline
\end{tabular}

\section{RESULTS AND DISCUSSIONS}

\subsection{TOOL WEAR}

Figure 2 shows a photograph of the tool edge observed using a digital microscope for a cutting speed $v_{c}$ of $300 \mathrm{~m} / \mathrm{min}$ and a cutting time $T$ of $59 \mathrm{~min}$. Tool wear was observed in the direction of the flank face side and, maximum width of flank wear land at tool corner $V B c$ was measured because the radial $a_{e}$ and axial $a_{p}$ depth of cuts were smaller than the tool nose radius $r_{e}$. Under all conditions, no adhesion or chipping was observed in the cutting edge, and abrasive wear was observed.

Figure 3 shows the relationship between the width of flank wear land as shown in Fig. 2 and the cutting time. The tool life was defined as the time when the width of flank wear land reached $50 \mu \mathrm{m}$. The obtained width of flank wear land $V B c$ increased with cutting time $T$ at all cutting speeds considered. Furthermore, the width of flank wear land increased as the cutting speed increased. Figure 4 shows a conceptual figure of the cutting edge, and the thickness $h$ of the DLC coating layer used in this study was $0.5 \mu \mathrm{m}$. From Fig. $4 \mathrm{~b}$, the width of flank wear land $V B c$ at which the base cemented carbide started to be exposed was approximately $7.6 \mu \mathrm{m}$. Therefore, cutting was mainly considered to be performed on 
the coating layer and the base material, because the width of flank wear land $V B c$, shown in Fig. 3, was $10 \mu \mathrm{m}$ or more at the initial stage of cutting.

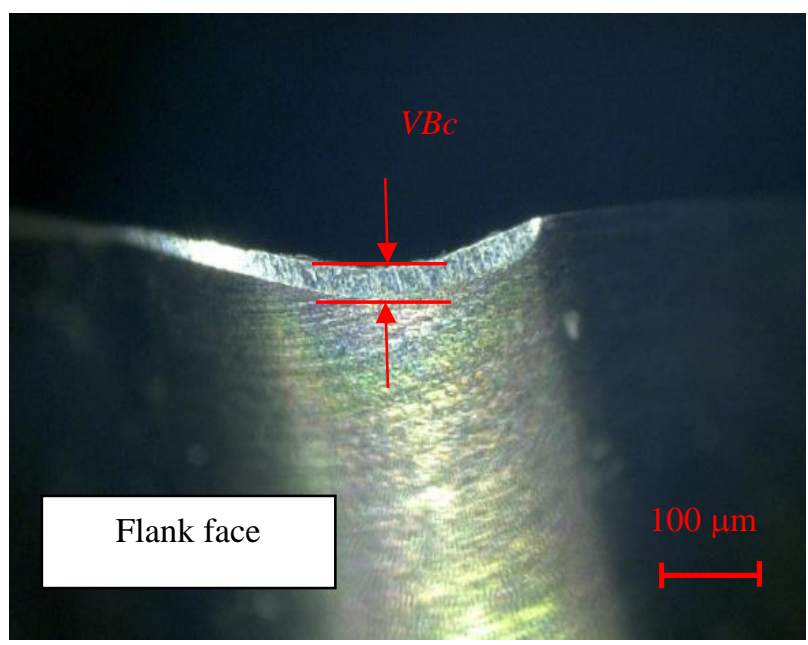

Fig. 2. Photograph of cutting edge $\left(v_{c}=300 \mathrm{~m} / \mathrm{min}, T=29 \mathrm{~min}\right)$

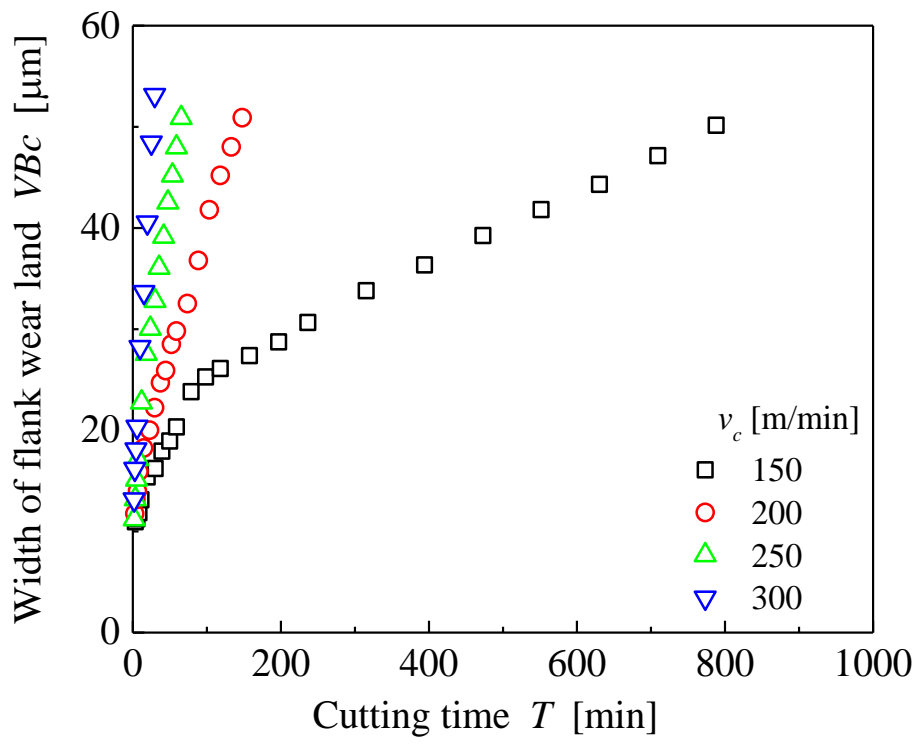

Fig. 3. Width of flank wear land

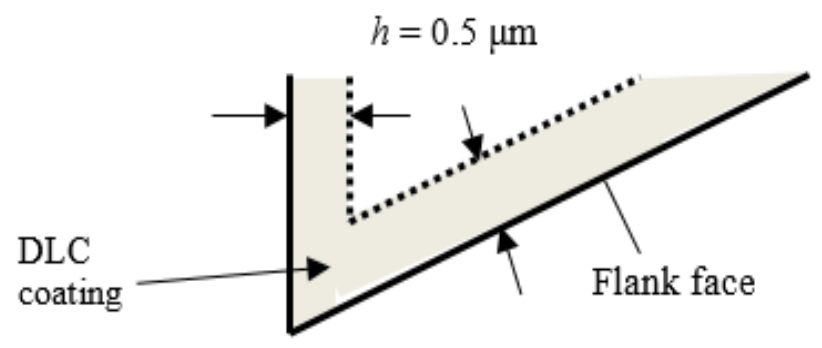

(a) New cutting edge

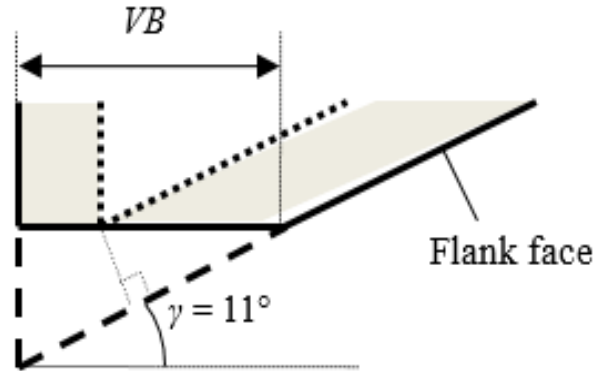

(b) Worn cutting edge

Fig. 4. Conceptual figure of DLC coated cutting edge 


\subsection{CUTTING FORCES}

The cutting forces $F_{x}, F_{y}$, and $F_{z}$ were measured in the direction shown in Fig. 1. Figure 5 shows the measured values of the cutting force components when the cutting speed $v_{c}$ is $300 \mathrm{~m} / \mathrm{min}$. The three components of cutting forces increased over time, and the change in the cutting force component $F_{x}$ was particularly remarkable.

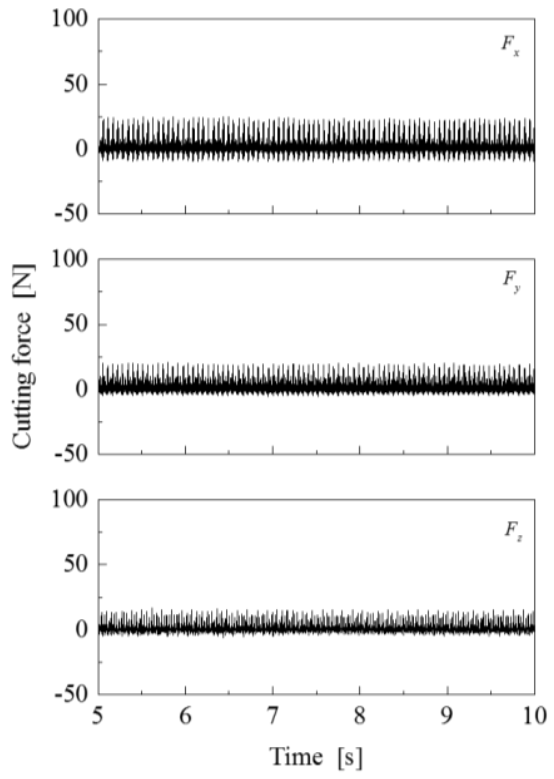

a) $2 \min$

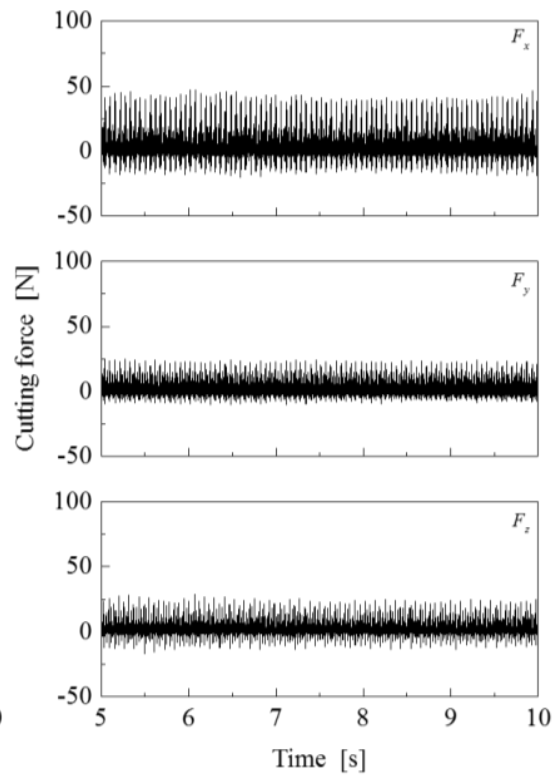

b) $10 \mathrm{~min}$

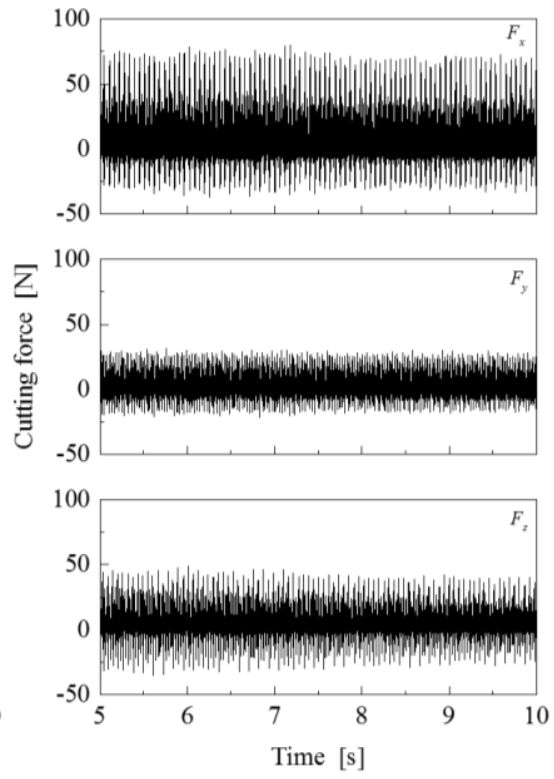

c) $30 \mathrm{~min}$

Fig. 5. Cutting force $\left(v_{c}=300 \mathrm{~m} / \mathrm{min}\right)$

The cutting forces directly attributable to the flank wear are consider as tangential and radial components. Therefore, the tangential cutting force $F_{c}$ and the radial cutting force $F_{p}$ were calculated. Figure 6 shows the conceptual figure of end milling with throw-away tip. When $\theta$ is the rotation angle, the tangential component force $F_{c}$ and the radial component force $F_{p}$ can be expressed by Equations (1) using $F_{x}$ and $F_{y}$ [17].

$$
\begin{aligned}
& F_{c}=F_{x} \sin \theta-F_{y} \cos \theta \\
& F_{p}=F_{x} \cos \theta+F_{y} \sin \theta
\end{aligned}
$$

Figure 7 shows the cutting force components calculated by Eq. (1) for one rotation of the end mill. The obtained cutting force components $F_{c}$ and $F_{p}$ were maximum at the same rotation angle of the chip. Therefore, the maximum value of the tangential and radial cutting forces were extracted and the average value was calculated. Figure 8 shows the relationship between the maximum value of cutting forces and the cutting time. The change trend of tangential cutting force $F_{c}$ increased with the cutting time $T$, and the change trend with the cutting time was similar to that of the width of flank wear land as shown in Fig. 3. Furthermore, the tangential cutting force $F_{c}$ at each cutting time increased with increasing cutting speed. On the other hand, the change trend of the radial cutting force $F_{p}$ with 
the cutting time, as shown in Fig. 8b was similar to that of the width of flank wear land as well as tangential cutting force $F_{c}$. From the above, the width of flank wear land $V B c$ is considered to be related to both the tangential cutting force $F_{c}$ and the radial cutting force $F_{p}$. Therefore, the ratio of radial cutting force to tangential cutting force $F_{p} / F_{c}$ was calculated, and its relationship with the width of flank wear land $V B c$ was investigated.

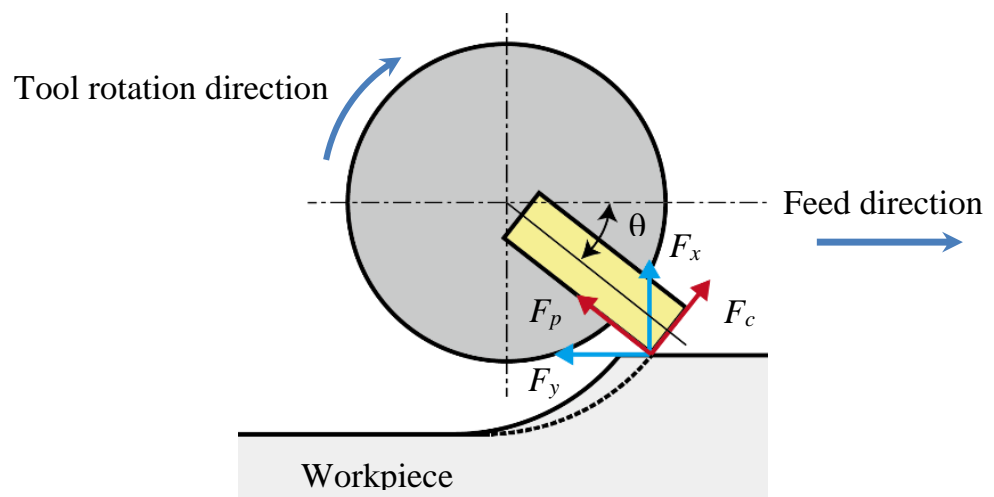

Fig. 6. Conceptual figure of end milling with throw-away tip

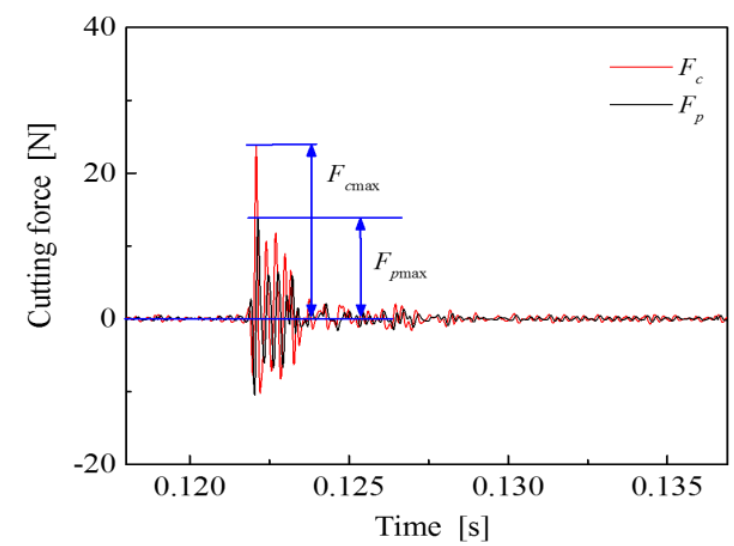

Fig. 7. Cutting force components for one rotation $\left(v_{\mathrm{c}}=300 \mathrm{~m} / \mathrm{min}, T=2 \mathrm{~min}\right)$

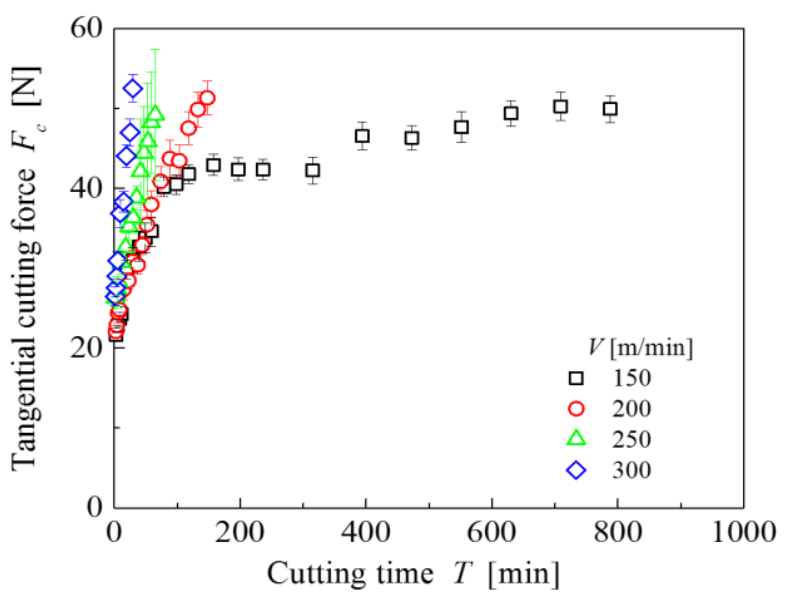

a) Tangential cutting force

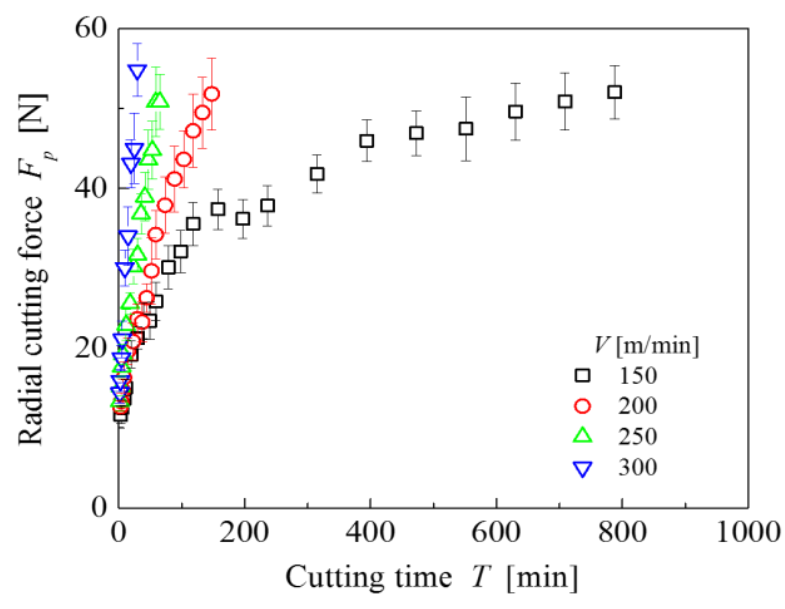

b) Radial cutting force

Fig. 8. Maximum value of cutting force 
Figure 9 shows the relationship between the cutting force ratio and the cutting time. The change trend of the calculated cutting force ratio $F_{p} / F_{c}$ was similar to that of the width of flank wear land $V B c$. Figure 10 shows the relationship between the cutting force ratio and the width of flank wear land. The width of flank wear land $V B c$ in Fig. 10 was approximately proportional to the cutting force ratio $F_{p} / F_{c}$ at all cutting speeds. The width of flank wear land $V B c$ was formulated as a function of the cutting force ratio $F_{p} / F_{c}$ by using a least-squares method and could be expressed by equation (2):

$$
V B c=K_{w}\left(\frac{F_{p}}{F_{c}}\right)^{n_{w}}
$$

The coefficient of determination $R^{2}$ is 0.96 , and it can be seen that the width of flank wear land shows a strong correlation with the cutting force ratio. From these results, it is clear that the width of flank wear land $V B$ can be estimated by monitoring the tangential cutting force $F_{c}$ and the radial cutting force $F_{p}$.

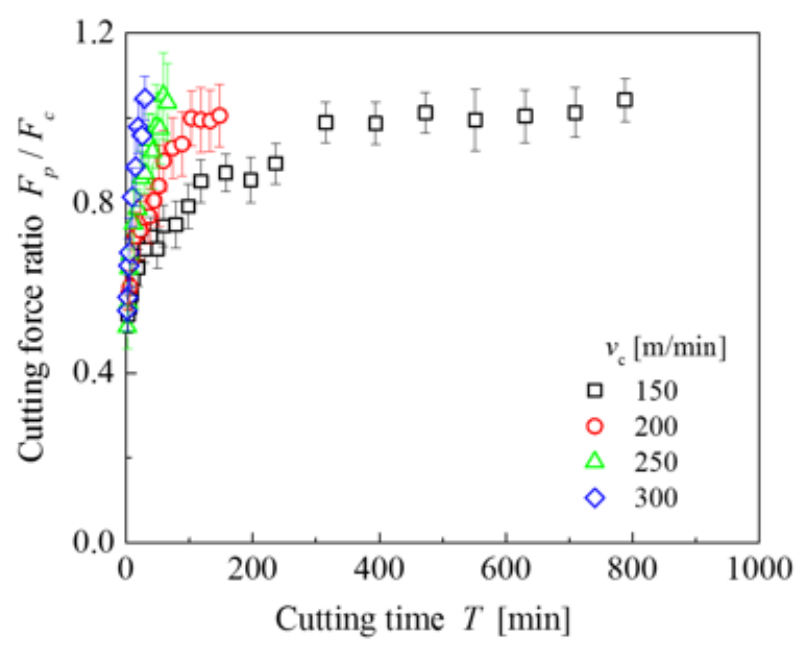

Fig. 9. Ratio of radial cutting force to tangential cutting force

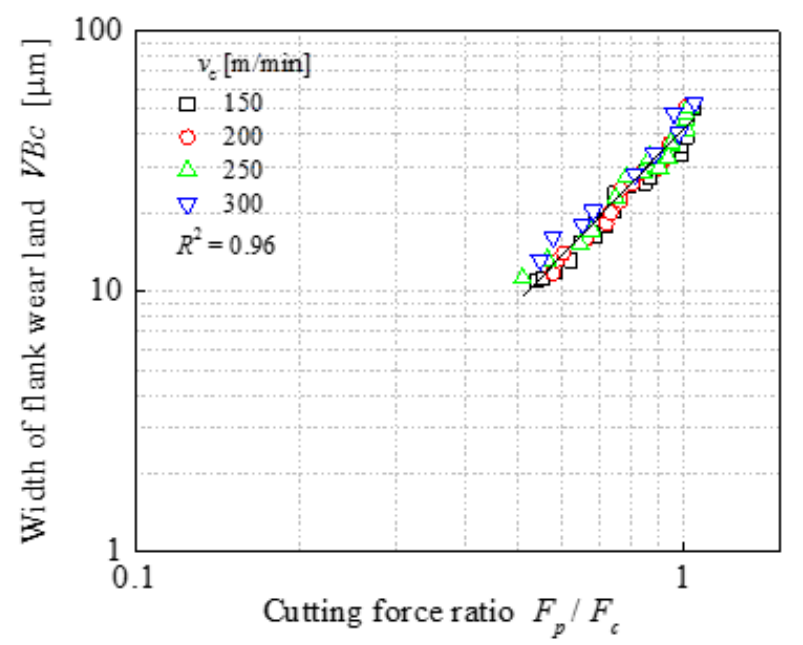

Fig. 10. Relationship between cutting force ratio and width of flank wear land 
Figure 11 shows the relationship between the cutting force ratio and the cutting time shown in Fig. 9 plotted on the logarithmic scale. At each cutting speed, the cutting force ratio increases monotonously with increasing distance, and it can be expressed as equation (3).

$$
\frac{F_{p}}{F_{c}}=K_{f} T^{n_{f}}
$$

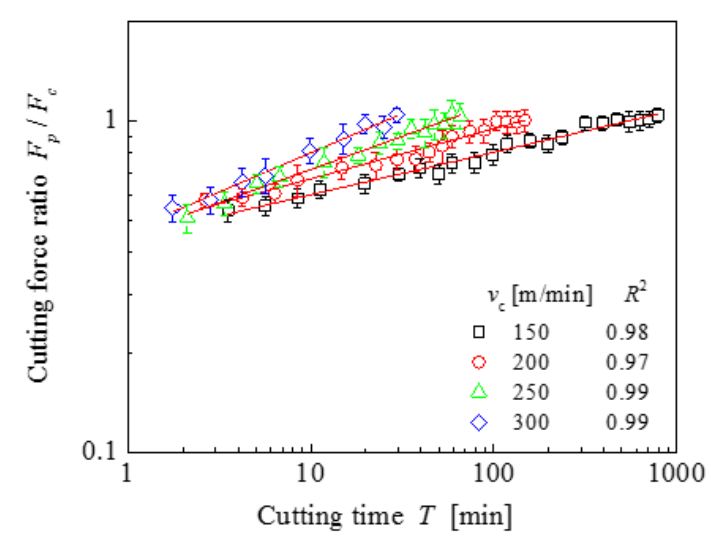

Fig. 11. Relationship between cutting force ratio and width of flank wear land (logarithmic scale)

Figure 12 shows the relationship between the coefficient of cutting force ratio and the cutting speed. The coefficient $K_{f}$ is approximately same under all cutting speeds $v_{\mathrm{c}}$. There, the coefficient $K_{f}$ is assumed to be 0.458 of the average value.

Figure 13 shows the relationship between the exponent of cutting force ratio and the cutting speed. It can be seen that the exponent of cutting force ratio $n_{f}$ is approximately proportional to the cutting speed, and the inclination as obtained by a least-squares method is $7.938 \times 10^{-4}$.

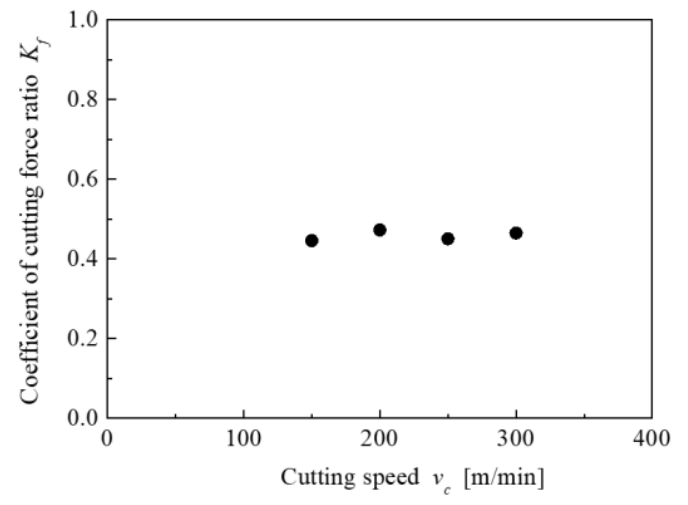

Fig. 12. Relationship between coefficient of cutting force ratio and cutting speed

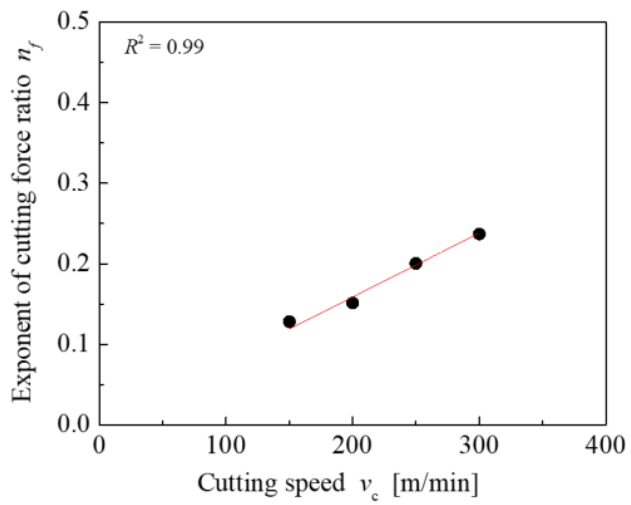

Fig. 13. Relationship between exponent of cutting force ratio and cutting speed

Therefore, from equations (2) and (3), the relationship between the width of flank wear land $V B$ and the cutting time $T$ can be expressed as follows:

$$
V B c=K T^{n}
$$


where

$$
\begin{gathered}
K=K 5_{w} K_{f}^{n_{w}} \\
n=n_{f} n_{w}
\end{gathered}
$$

Equation (4) yields the same results as the face cutting of single crystal silicon that we have performed, and it is considered that the main cause of tool wear is due to silicon particles [18].

Table 2 shows the coefficient and exponent of the width of flank wear land obtained in this study. Figure 14 shows the relationship between the width of flank wear land $V B c$ and the cutting time $T$ shown in Fig 3. The solid line in this figure represents the width of tool wear calculated by equation (4).

Table 2. Coefficient and exponent of width of flank wear land

\begin{tabular}{|c|c|c|c|c|c|}
\hline$K_{w}$ & $K_{f}$ & $K$ & $n_{w}$ & $n_{f}$ & $n$ \\
\hline 42.198 & 0.458 & 7.531 & 2.197 & $7.938 \times 10^{-4} v_{c}$ & $1.754 \times 10^{-3} v_{c}$ \\
\hline
\end{tabular}

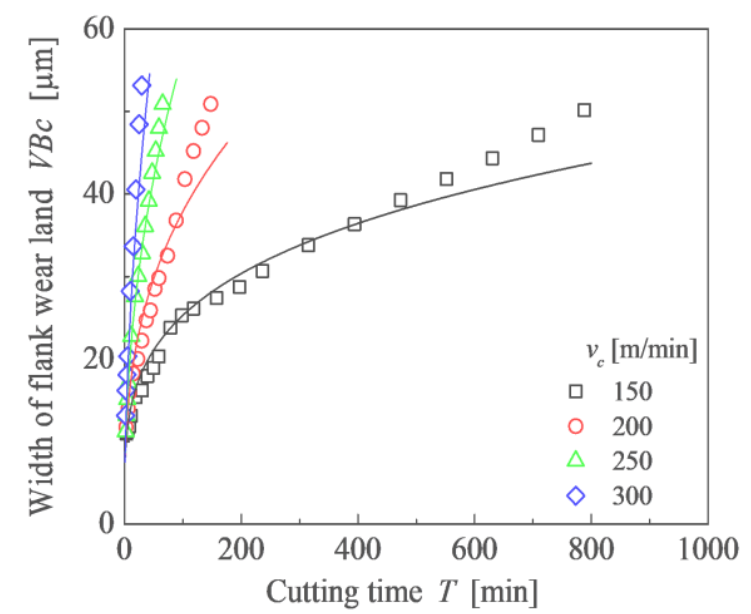

Fig. 14. Relationship between width of flank wear land and cutting time

When the cutting speeds are 250 and $300 \mathrm{~m} / \mathrm{min}$, the calculated width of flank wear land approximately coincides with the experimental width of flank wear land. On the other hand, for cutting speeds of 150 and $200 \mathrm{~m} / \mathrm{min}$, the calculated width of the flank wear land coincides with the experimental value below $V B c=40 \mu \mathrm{m}$, whereas they differ at above $V B c=40 \mu \mathrm{m}$. Therefore, if the width of flank wear at each cutting speed and time is $40 \mu \mathrm{m}$ or less, it can be approximated using Equation (4). Future works should clarify the effect of the feed rate and depth of cut on tool wear.

\section{CONCLUSIONS}

End milling of hypereutectic Al-Si alloy with silicon content of 17\% (A390-T6) was conducted using DLC coated carbide tools to investigate the relationship between tool wear 
and cutting force, cutting speed, and cutting distance. The results obtained in this study are summarized as follows.

1. The measured cutting force components $F_{x}, F_{y}$, and $F_{z}$ and the calculated tangential and radial cutting forces $F_{c}$ and $F_{p}$ increased with tool wear. In particular, the ratio of radial cutting force to tangential cutting force $F_{p} / F_{c}$ was correlated significantly with the width of flank wear land, which had little effect on cutting speed.

2. The experimental equation of the width of flank wear land was derived as a function of cutting speed and time, which approximately coincided with the measured width of flank wear land. As a result, the width of flank wear land can be estimated.

\section{REFERENCES}

[1] JAVIDANI M., LAROUCHE D., 2014, Application of Cast Al-Si Alloys in Internal Combustion Engine Components, Int. Mater. Rev., 59/3, 132-158.

[2] VIJAYAN V., PRABHU K., 2014, Review of Microstructure Evolution in Hypereutectic Al-Si Alloys and Its Effect on Wear Properties, Trans. Indian Inst. Met., 67/1, 1-18.

[3] HOSOKAWA A., HIROSE N., UEDA T., FURUMOTO T., 2014, High-Quality Machining of CFRP with High Helix End Mill, CIRP Annals - Manufacturing Technology, 63, 89-92.

[4] UCUN I., ASLANTAS K., BEDIR F., The Performance of DLC-Coated and Uncoated Ultra-Fine Carbide Tools in Micromilling of Inconel 718, 2015, Precision Engineering, 41, 135-144.

[5] PATIL P., POLISHETTY A., GOLDBERG M., LITTLEFAIR G., NOMANI J., 2014, Slot Machining of TI6AL4V with Trochoidal Milling Technique, Journal of Machine Engineering, 14/4, 42-54.

[6] GRZESIK W., NIESLONY P., HABRAT W., LASKOWSKI P., 2015, Influence of Cutting Conditions on Temperature Distribution in Face Milling of Inconel 718 Nickel-Chromium Alloy, Journal of Machine Engineering, $15 / 2,5-16$.

[7] ARUMUGAM U.P., MALSHE P.A., BATZE S., 2006, Dry Machining of Aluminum-Silicon Alloy Using Polished CVD Diamond-Coated Cutting Tools Inserts, Surface and Coatings Technology, 200/11, 3399-3403.

[8] LIU J., CHOU Y.K., 2007, On Temperatures and Tool Wear in Machining Hypereutectic Al-Si Alloys with Vortex -Tube Cooling, International Journal of Machine Tools and Manufacture, 47, 3/4, 635-645.

[9] LIANG Q., VOHRA K.Y., THOMPSON R., 2008, High Speed Continuous and Interrupted Dry Turning of A390 Aluminum/Silicon Alloy Using Nanostructured Diamond Coated WC-6 wt. \% Cobalt Tool Inserts by MPCVD, Diamond and Related Materials, 17/12, 2041-2047.

[10] BARTOSZUK M., GRZESIK W., 2015, Investigation of Initial Wear Period of Differently Coated Carbide Cutting Tools, Journal of Machine Engineering, 15/4, 37-45.

[11] BOUZAKIS K.D., MICHAILIDIS N., SKORDARIS G., BOUZAKIS E., BIERMANN D., M'SAOUBI R., 2012, Cutting with Coated Tools: Coating Technologies, Characterization Methods and Performance Optimization, CIRP Annals - Manufacturing Technology, 61, 703-723.

[12] BHOWMICK S., BANERJI A., ALPAS T.A., 2015, Tribological Behaviour of Al-6.5\%, $-12 \%,-18.5 \%$ Si Alloys During Machining Using CVD Diamond and DLC Coated Tools, Surface and Coatings Technology, 284, 353-364.

[13] BHOWMICK S., LUKITSCH T. A., ALPAS T.A., 2010, Tapping of Al-Si Alloys with Diamond-Like Carbon Coated Tools and Minimum Quantity Lubrication, Journal of Materials Processing Technology, 210, 2142-2153.

[14] FOLEA M., ROMAN A., LUPULESCU N., 2010, An Overview of DLC Coatings on Cutting Tools Performance, Academic Journal of Manufacturing Engineering, 8/3, 30-36.

[15] SANTOS R.G., COSTA D.D., AMORIM L.F., TORRES D.R., 2007, Characterization of DLC Thin Film and Evaluation of Machining Forces Using Coated Inserts in Turning of Al-Si Alloys, Surface and Coatings Technology, 202, 1029-1033.

[16] OTHMAN K., GHANI A.J., RUSLAN S.M., KASSIM S.M., 2018, Surface Roughness of Hypereutectic Al-Si A390 in High Speed Milling, Journal Tribology, 16, 42-50.

[17] KANG S.I., KIM S.J., KIM H.J., KANG C.M., SEO W.Y., 2007, A Mechanistic Model of Cutting Force in the Micro End Milling, J. Mater. Process. Tech., 187-188, 250-255.

[18] KOBARU Y., KONDO E., IWAMOTO R., 2017, Precision Cutting of Single Crystal Silicon Using CBN Tool with Large Top Corner Radius, International Journal of Nanomanufacturing, 13/2, 170-184. 